\title{
Normalising or Equalising Party Competition? Assessing the Impact of the Web on Election Campaigning
}

\author{
Rachel K. Gibson \\ University of Manchester
}

\author{
Ian McAllister \\ Australian National University
}

A core question addressed by parties and internet scholars is whether the medium is equalising or normalising levels of inter-party competition, Are minor parties better placed to compete for voters' attention online (equalisation), or do major parties continue to dominate (normalisation)? To date, most research has supported the latter scenario through 'supply-side' comparisons of website content in a single election. This article re-examines the debate using Australian surveys of election candidates conducted between 2001 and 2010. As well as providing the first longitudinal study of this question, we link the supply side with voter responses and compare how well the parties recruit support through their web campaigns. Our results confirm that major parties dominate in the adoption of personal websites, although minor parties are stronger users of social media. Both strategies are effective in gaining votes, suggesting that the web may be rebalancing if not equalising party competition.

Keywords: political parties; internet; campaigning; digital; normalisation

The increasing use of the internet as a political communication medium led to considerable speculation about the possibilities for a new social and political order that would involve the redistribution of power away from established players, and out toward previously unheard and marginalised voices in society (Castells, 1996; Dahlberg, 2001; Negroponte, 1995; Rheingold, 1993). In the context of political parties this prospect formed a particularly compelling theme for research and led to development of the 'equalisation' thesis, which argued that in the online environment smaller parties were able to overcome the disadvantages they typically faced in the offline media environment and could more effectively communicate their message to a wider audience (Corrado and Firestone, 1996).

Initial empirical research appeared to support the equalisation thesis (Gibson and Ward, 1998; Margolis et al., 1999). However, subsequent studies reported a pattern of dominance by the major parties that became labelled the 'normalisation' thesis. Instead of an equalisation in offline patterns of inter-competition occurring online, current imbalances were simply being replicated (Gibson et al., 2003a; 2003b; Newell, 2001; Tkach-Kawasaki, 2003). Growing web use among voters meant that the larger parties increasingly saw the added value of online campaigning and were prepared to invest in it. By the middle of the last decade most studies appeared to point toward the conclusion that normalisation had indeed become the 'norm', and the internet was not providing any obvious benefit to smaller parties.

The normalisation perspective continued to gain support in analyses of party and candidate home pages conducted over the past decade (Lilleker et al., 2011; Schweitzer, 2008; 2011; Small, 2008; Vaccari, 2008). However, some authors have pointed to the possibility of a return to the equalisation scenario with the rise of Web 2.0 or social media 
tools (Gueorguieva, 2008; Kalnes, 2009; Strandberg, 2009). These highly popular social spaces offer a much cheaper platform for parties and candidates to establish a presence compared with the investment required for purpose-built personalised websites. Using Facebook and Twitter, smaller parties can organise their existing supporters better and potentially connect to a wider and younger audience than that to which they might otherwise have had access. ${ }^{1}$ Such efforts might ultimately help to improve their electoral prospects.

This study develops our understanding of the normalisation vs. equalisation debate in the context of inter-party competition in several key ways. First, we re-present and test the arguments as a cyclical hypothesis which explains parties' use of the web over time, rather than as competing individual explanations applied at a single time point - usually national elections. We see this as a more nuanced and accurate interpretation of the debate to date. We do so using a unique data source that measures website and social media adoption by Australian election candidates across four elections. Second, we combine this 'top-down' perspective with an analysis of electoral outcomes to measure the impact of web campaigns on popular support. This extension from a 'supply-side' study to one examining 'demand' or voter responsiveness permits a more comprehensive assessment of the equalisationnormalisation thesis. More specifically, although patterns of adoption among elites may suggest that major parties have an advantage in regard to the provision of web campaigning, if this does not lead to any electoral gains then it becomes questionable whether the activity is actually reinforcing their position of dominance. Conversely, if smaller parties are capitalising on their digital campaign efforts but not gaining any inroads into popular support, then it becomes difficult to see how this is leading to a rebalancing of power within the system. By extending the time period covered and looking beyond simply web presence to impact, our analysis provides the most robust and comprehensive test of the normalisation-equalisation debate than has previously been conducted.

\section{Equalisation and Normalisation Perspectives}

The idea that the internet would redistribute power from established elites to more marginalised groups is not confined to the study of political parties. From the early 1990s onward scholars heralded the internet's democratising implications (Dahlberg, 2001; Negroponte, 1995; Rheingold, 1993). Early moves by parties in the UK and US in particular prompted speculation that party systems would see a rebalancing of power toward the minor players. The internet, with its low entry costs and fast and unmediated reach into people's homes, presented an opportunity for those marginalised by the established media to convey their message to a wider audience (Corrado and Firestone, 1996; Gibson and Ward, 1998; Rash, 1997). Initial empirical evidence tended to support the equalisation thesis. Rachel Gibson and Stephen Ward's (1998, p. 22) study of the 1997 UK general election, for example, concluded that 'far from leaving the minor parties in the dust the internet appears to be doing more to equalize exposure of parties' ideas to the electorate compared to other media'.

As the empirical evidence began to accumulate, the expectation of a more level playing field came under increasing pressure as studies of party sites in national elections revealed a growing dominance by the major parties (Conway and Domer, 2004; Gibson et al., 
2003a; Semetko and Krasnoboka, 2003; Ward and Gibson, 1999). Based mainly on comparisons of website content, these studies pointed to a trend whereby the larger, well-resourced parties ran better designed multi-functional sites which delivered more information and greater opportunities for participation and financial donations. The findings were seen as countering the earlier findings of equalisation and leading instead to a scenario of 'normalisation' whereby internet use shored up the power of existing elites (Margolis and Resnick, 2000). Outside the party sphere the argument had particular resonance at the individual level where a digital divide was quickly identified in favour of higher socio-economic status citizens who were already active in political and civic life (Norris, 2001; 2003).

Conclusions about a normalisation and reinforcement of the power of existing elites resulting from the adoption of digital tools has continued to gain support in the online parties literature (Carlson and Strandberg, 2005; Jackson, 2007; Koc-Michalska and Vedel, 2009; Small, 2008; Strandberg, 2009; Vaccari, 2008; Williams and Gulati, 2007), although some exceptions to these trends have been noted, suggesting that a 'third way' between the poles of normalisation and equalisation may be emerging. Green parties in particular have been found to offer sites that often rival those of the major parties in terms of the richness of their content and levels of interactivity (Conway and Domer, 2004; Gibson and Ward, 2003; Gibson et al., 2003a; 2003b; Newell, 2001; Norris, 2001; Schweitzer, 2005; 2008; Tkach-Kawasaki, 2003). The far right has also been notable in its efforts to utilise the web to communicate with supporters. The medium is typically seen as offering considerable benefits for such parties due to the anonymity it provides to users in accessing and exchanging information and also in the way it allows them to bypass the traditional media which they see as either ignoring or distorting their message (Bratten, 2005; Caiani and Parenti, 2009; Whine, 2000).

While most of the studies supporting normalisation have been based on comparing website contents, a small number have introduced some 'demand-side' evidence and examined how far these sites may be contributing to smaller parties' success at the ballot box. Overall these analyses have generally pointed further toward normalisation and the lack of any clear shift in party power relations. Ward's (2011) analysis of fringe parties' success in the pre- and post-internet era in British Columbia showed that the success of fringe parties remained fairly constant across the two periods and seemed largely unrelated to website establishment. Other studies have profiled the audience for party websites and found that, far from reaching new pockets of the electorate, party websites are consumed by a very small and select audience, with higher levels of political interest and partisanship than average users (Gibson et al., 2010; Koc-Michalska and Vedel, 2009; Smith and Rainie, 2008; Ward and Lusoli, 2005).

In the face of this mounting evidence that 'party politics as usual' was emerging online, the recent growth of social media has provided some fresh impetus to expectations for an equalising of power relations. The networked and viral nature of Web 2.0 technologies like Facebook, Twitter and YouTube are seen as throwing a lifeline to less advantaged minor parties which lack access to mainstream news outlets and the resources to build an organisational infrastructure (Gueorguieva, 2008). Such platforms allow for a wider communication reach and, perhaps even more importantly, for the establishment of new 
supporter hubs and the building of a 'virtual' or even physical local infrastructure. The initial success of Howard Dean in the 2004 Democratic primaries in the US was widely attributed to his team's skilful use of social media tools to establish organisations across all 50 states (Harfoush, 2009; Hindman, 2009; Trippi, 2004). Similarly, Barack Obama's victory over the expected winner, Hillary Clinton, in the 2008 Democratic primaries fuelled the idea that the new wave of digital tools could transform the fortunes of the 'underdog' (Gibson, 2013).

Beyond the US, studies of Scandinavian parties' use of social media tools have concluded that minor parties are at least as active on these platforms as their major party counterparts (Carlson and Strandberg, 2008; Kalnes, 2009). Finally, the increasing success of pirate parties in national elections across a number of major democracies since 2009 provides a further impetus for hopes of an equalisation of party competition in the digital age. Spawned precisely from a desire to protect internet freedoms in Sweden, the Pirate Party has become a worldwide political franchise with sister parties in over ten countries (Erlingsson and Persson, 2011). In 2013 the Icelandic Pirate Party gained the largest vote share to date in a national election, securing 5 per cent.

In summary, research on the impact of the web on inter-party competition to date has suggested a cycle of innovation whereby adoption first leads to more equalised relations between major and minor parties in the mid-1990s. This then gives way to a more normalised 'major party dominant' environment by early 2000, which then swings back to a position of equalisation as parties moved into the Web 2.0 era, starting around 2005. The evidence supporting this dynamic, however, has been based on cumulated snapshots of individual elections across a range of countries. In addition, studies have often focused on the content of national party web pages as measures of web dominance. A missing component is the assessment of whether the differences observed in the quality of web campaign performance actually translate into electoral support. For normalisation to occur not only should major parties have a better web presence, but this should also be linked to an electoral advantage. Conversely, for equalisation to be taking place, smaller parties should not only be able to match their major competitors on 'supply' terms but also be able to use this to increase their levels of popular support. Without investigating the demand side or the effect on voters, therefore, conclusions about a normalisation of web campaigning or redistribution toward more marginal players are, at best, incomplete.

\section{Testing Web Campaign Cycles in Australia}

This study provides the first over-time test of the normalisation and equalisation scenarios in relation to party web campaigning and also the first test of these arguments at both the elite and voter levels. As a first step, we chart the supply-side trends among Australian major and minor party candidates across the four consecutive elections covering the transition from the Web 1.0 to the Web 2.0 era. Despite accusations of a lack of specificity, ${ }^{2}$ the terms Web 1.0 and 2.0 have gained currency within the social science literature as a means of capturing an important shift in citizens' use of the internet circa 2005. Essentially, the transition involved a move from an era when web content was dominated by static web pages that individuals passively consumed to a more interactive experience where users could create, exchange and edit content to share within their own 
networks and with the wider online public (Chadwick, 2009; Gueorguieva, 2008; O'Reilly, 2005). Embodied by the new social networking and video-sharing sites such as Facebook and YouTube, Web 2.0 was seen to herald a new more participatory ethos and culture of 'sharing' which led to the label of 'social media' being applied. The two terms are used interchangeably here.

Given that our time period starts in 2001, we begin with an expectation of major party dominance in 2001 and 2004 with the situation changing in 2007 and 2010 when smaller parties are expected to exploit the new social media tools more extensively. We then examine the findings in 2007 and 2010 from a demand perspective, evaluating how far the parties' use of the different tools influenced their electoral support. To test the cyclical hypothesis it is necessary to have data on the use of web campaigning over successive elections that differentiate the types of tool that are being used by the various parties. These data are available in the unique resource of the Australian Candidate Study (ACS), which is a survey of all national election candidates which has been conducted since 1987 (see Appendix for details). Since 2001, the ACS has asked questions about candidates' use of the web during election campaigns. In 2001 and 2004 the ACS includes a simple binary measure of whether a personal website was used by the candidate. The 2007 and 2010 surveys repeat this question and add a range of newer tools such as blogs, social network sites and Twitter. This allows us to test whether the Web 1.0 era was one of major party dominance which is now being challenged in the Web 2.0 era. After charting the cycle of web campaign adoption in Australia across time we then investigate normalisation or equalisation through the lens of voter responses. If parties are found systematically to favour certain types of web campaigning over others, does this matter for their electoral success? Even if the minor parties do show a stronger use of social media, do they benefit electorally from their investment in these tools?

The analyses are based on candidates standing for the Liberal, National, Labor and Green Parties for the lower House of Representatives. The Liberal and National Parties have been in almost permanent coalition since 1923, and accordingly we treat them as a single group. ${ }^{3}$ These two parties represent the conservative side of Australian politics. The Australian Labor Party is the main centre-left party with a continuous history dating back to the late nineteenth century. Together, the Liberal-National coalition and the Labor Party have dominated Australian politics for almost a century in what has been in practice a two-party system. The Greens have been the largest minor party in recent elections, eclipsing the now-disbanded Australian Democrats in the early 2000s. In recent elections the Greens have contested almost all lower house seats, although they did not win a lower house seat until 2010. ${ }^{4}$

The fact that Australia has a system of compulsory voting which has operated in national elections since 1924 makes this analysis particularly useful as a case study. First, it means that any effects of web campaigns are not generated from mobilising non-voters to go to the polls but rather from converting the preferences of existing voters. This arguably makes it harder for campaigners in general to recruit new support and thus for researchers to detect any significant effects. Second, given that enrolled citizens are required to attend the polls (and around 95 per cent do so in each national election) this means that our results are unaffected by problems of differential turnout between certain groups. ${ }^{5}$ 
Before moving to test the cyclical hypothesis in terms of uptake of web campaign tools, we first use the ACS to profile the differences between the candidates of major and minor parties in their personal use of the web during election campaigns and their overall enthusiasm for the technology as a campaign tool. On the first measure, as Table 1 shows, candidates' use of the internet for election news overall is very high. In 2001 no less than 87 per cent of Labor candidates and 73 per cent of Liberal-National candidates reported using the internet for election news 'many times'. Interestingly this compares to just 1 per cent of voters in the same election, demonstrating a stark digital divide between political elites and the public. This disparity in usage has narrowed over time with access rates increasing significantly over the course of the decade. According to the Australian Election Study of 2010, 36 per cent of voters had gone online for news and information during the campaign, with 10 per cent having done this many times. Of course this is still a minority of the population and serves as a limitation on any web campaign effects. We return to this point below when we examine the electoral impact of different types of web campaigning in relation to the normalisation and equalisation hypotheses. Most interesting from our perspective, however, is the finding that Green candidates were significantly less likely to use the internet for election information at the start of the period studied than candidates from either of the two major parties. By the next election cycle, however, this difference had disappeared and parity was maintained through to 2010. These findings suggest that an initial digital divide was operating between minor and major party candidates in their own use of the web which has flattened subsequently.

This slower rate of personal adoption and use of the technology by Green candidates is not reflected in their views on its importance for campaigning. Table 2 shows that while the internet is generally regarded as the least important campaign medium compared with print and other electronic media, Green candidates have consistently rated it as more important compared to their major party rivals. However, by 2010 the gap had narrowed considerably. In this election, for the first time, a majority of major party candidates considered the web to be an 'extremely' or 'very important' means of communicating with voters. This spike of interest in the internet as a campaign medium is also reflected in an increase in preferences for radio and to a lesser extent newspaper communication. Conversely, television's importance fell slightly. Whether this was a one-off event or reflects a wider trend in the declining appeal of television as a 'broadcast' medium compared with other more targeted and 'narrowcasting' channels is for future research to explore.

Overall, these findings show that despite the more sluggish personal use of the new media by smaller party candidates, they are positively disposed to it as a campaign medium, and place a greater value on it as a means of conveying their message during an election compared to their major party counterparts. The latter have clearly been warming to the technology, and by 2010 the internet had 'arrived' in that a majority of candidates now considered it to be a highly valuable communication tool. As such, the findings do provide some support for the logic of equalisation in terms of smaller parties placing more value on the medium across the entire period of our study. In terms of our cyclical hypothesis, however, the results suggest that a more normalised situation has emerged in the post-Web 2.0 era with the larger parties now understanding its importance and being prepared to invest in the technology. 
Table 1: Candidates' Use of the Internet for Election News, 2001-10 (per cent)

\begin{tabular}{|c|c|c|c|}
\hline & Lib-Nat & Labor & Green \\
\hline \multicolumn{4}{|l|}{2001} \\
\hline Yes, many times & 73 & 87 & 56 \\
\hline Yes, several occasions & 17 & 6 & 25 \\
\hline Yes, once or twice & 3 & 4 & 7 \\
\hline Access but did not use for election information & 4 & 2 & 6 \\
\hline No internet access & 3 & 1 & 7 \\
\hline Total & 100 & 100 & 100 \\
\hline \multirow[t]{2}{*}{$\mathrm{N}$} & 71 & 69 & 89 \\
\hline & \multicolumn{3}{|c|}{ (Chi-sq $=19.85, p=0.01$ ) } \\
\hline \multicolumn{4}{|l|}{2004} \\
\hline Yes, many times & 73 & 79 & 75 \\
\hline Yes, several occasions & 12 & 14 & 17 \\
\hline Yes, once or twice & 3 & 3 & 5 \\
\hline Access but did not use for election information & 12 & 3 & 1 \\
\hline No internet access & 0 & 1 & 2 \\
\hline Total & 100 & 100 & 100 \\
\hline \multirow[t]{2}{*}{$\mathrm{N}$} & 67 & 70 & 103 \\
\hline & \multicolumn{3}{|c|}{ (Chi-sq $=14.14, p=0.08$ ) } \\
\hline \multicolumn{4}{|l|}{2007} \\
\hline Yes, many times & 77 & 85 & 83 \\
\hline Yes, several occasions & 12 & 13 & 9 \\
\hline Yes, once or twice & 8 & 3 & 7 \\
\hline Access but did not use for election information & 3 & 0 & 1 \\
\hline No internet access & 0 & 0 & 1 \\
\hline Total & 100 & 100 & 100 \\
\hline \multirow[t]{2}{*}{$\mathrm{N}$} & 60 & 71 & 103 \\
\hline & \multicolumn{3}{|c|}{ (Chi-sq $=7.03, p=0.53$ ) } \\
\hline \multicolumn{4}{|l|}{2010} \\
\hline Yes, many times & 91 & 85 & 83 \\
\hline Yes, several occasions & 7 & 8 & 11 \\
\hline Yes, once or twice & 2 & 4 & 6 \\
\hline Access but did not use for election information & 0 & 3 & 0 \\
\hline No internet access & 0 & 0 & 0 \\
\hline Total & 100 & 100 & 100 \\
\hline \multirow[t]{2}{*}{$\mathrm{N}$} & 53 & 60 & 93 \\
\hline & \multicolumn{3}{|c|}{ (Chi-sq $=7.37, p=0.29$ ) } \\
\hline
\end{tabular}

Notes: The question was: 'Did you make use of the internet at all to get news or information about the [2001, 2004, 2007, 2010] federal election?' Totals not always exactly 100 due to rounding up.

Sources: Australian Candidate Studies, 2001-10. 
Table 2: Importance of Media for Election Campaigning, 2001-10 (per cent)

\begin{tabular}{|c|c|c|c|c|}
\hline & Lib-Nat & Labor & Green & \\
\hline \multicolumn{5}{|l|}{2001} \\
\hline Television & 67 & 73 & 70 & $($ Chi-sq $=0.55 p=0.76)$ \\
\hline Radio & 59 & 58 & 55 & (Chi-sq $=0.55 p=0.76$ ) \\
\hline Newspapers & 67 & 51 & 75 & (Chi-sq $=10.21 p=0.01$ ) \\
\hline Internet & 5 & 15 & 17 & (Chi-sq $=14.96 p=<0.00)$ \\
\hline \multicolumn{5}{|l|}{2004} \\
\hline Television & 71 & 83 & 70 & (Chi-sq $=4.13 p=0.13$ ) \\
\hline Radio & 61 & 57 & 52 & (Chi-sq $=1.14 p=0.57)$ \\
\hline Newspapers & 58 & 57 & 73 & (Chi-sq $=6.34 p=0.04$ ) \\
\hline Internet & 9 & 12 & 34 & (Chi-sq $=19.92 p=<0.00)$ \\
\hline \multicolumn{5}{|l|}{2007} \\
\hline Television & 75 & 78 & 67 & (Chi-sq $=2.98 p=0.23$ ) \\
\hline Radio & 60 & 55 & 50 & (Chi-sq $=1.63 p=0.44)$ \\
\hline Newspapers & 56 & 47 & 70 & (Chi-sq $=9.37 p=0.01)$ \\
\hline Internet & 22 & 17 & 38 & (Chi-sq $=10.33 p=0.01$ ) \\
\hline \multicolumn{5}{|l|}{2010} \\
\hline Television & 65 & 61 & 70 & (Chi-sq $=1.33 p=0.52$ ) \\
\hline Radio & 69 & 63 & 74 & (Chi-sq $=2.34 p=0.31)$ \\
\hline Newspapers & 72 & 71 & 85 & (Chi-sq $=5.02 p=0.08$ ) \\
\hline Internet & 56 & 51 & 74 & (Chi-sq $=9.64 p=0.01)$ \\
\hline
\end{tabular}

Notes: The question was: 'In the election campaign generally, how important would you rate the following media for campaigning?' See Table 1 for the number of cases, which varies slightly for individual items due to missing data. The \% are based on the number of candidates who said the media in question were 'extremely important' or 'very important'.

Sources: Australian Candidate Studies, 2001-10.

To explore this finding further we turn to look at candidates' actual deployment of the technology in elections. ${ }^{6}$ Here we look first at the measures of personal website use across the full time period. We then turn to show the results of social media adoption. Table 3 presents the results for the use of a personal website - that is, one that is purpose-built for them and independent of any party-provided pages. The results show a consistent pattern of dominance by major party candidates, with a marked trend towards an increasing use of a personal web page in each successive election.

In 2001 just over two-fifths (41 per cent) of Labor candidates reported using a personal web page; by 2010 that figure had increased to over two-thirds. In 2010 more than eight out of every ten Liberal-National candidates reported having a personal web page. By contrast, Green candidates' use of personal web pages has been more modest, with the partial exception of the 2004 election. ${ }^{7}$ Indeed, in three of the four elections, the rate of Green candidates' use of personal web pages has been less than half that of the major party candidates.

These results provide a useful complement to those reported in Table 2 in that they show that despite minor party candidates being more likely to regard the internet as 
Table 3: Candidates Maintaining a Personal Campaign Website, 2001-10 (per cent)

\begin{tabular}{|c|c|c|c|c|}
\hline & Lib-Nat & Labor & Green & \\
\hline 2001 & 56 & 41 & 26 & $($ Chi-sq $=14.96 p=<0.00)$ \\
\hline 2004 & 53 & 42 & 55 & (Chi-sq $=3.13 p=0.21$ ) \\
\hline 2007 & 64 & 49 & 27 & $($ Chi-sq $=22.90 p=<0.00)$ \\
\hline 2010 & 83 & 69 & 31 & $($ Chi-sq $=42.22 p=<0.00)$ \\
\hline
\end{tabular}

Notes: The questions were: $(2001,2004)$ 'Did you maintain a personal website on the internet as part of your election campaign in the electorate?' (2007) 'Did you provide any of the following services during the election campaign? ... personal website?' (2010) 'Below is a list of internet-related tools that can be used to communicate with voters during elections. For each one please say how important they were for you in the election campaign ... personal website (independent of party)'. See Table 1 for the number of cases, which varies slightly for individual items due to missing data.

Sources: Australian Candidate Studies, 2001-10.

electorally important, their actual use of the technology - in the form of personal websites - has lagged behind that of the major parties, and this pattern has intensified in recent years. Major party candidates, by contrast, while not regarding the web as a particularly important aspect of their overall campaign, consistently outnumber the Greens online. In general the results provide strong support for the normalisation thesis as the dominant trend across the time period. Personal websites, while not necessarily financially out of reach for small party candidates, are more expensive than email and Web 2.0 platforms to establish and maintain. Individual home pages require a domain name to be bought and original site content to be developed and designed. Twitter, Facebook and blogs can be used at no cost and work largely through templates, providing the user with preset designs to choose from and an easy content management system. Moreover, it is clear from a brief look at the archives of party websites on the Wayback Machine (http://www.archive.org) that the professional quality of websites has risen, leading to a strong implication that the resources of time and money needed for those seeking to maintain this type of personalised presence have similarly grown.

Once we unpack the data from the two most recent elections (2007 and 2010), which include measures of candidates' use of Web 2.0, as expected a different picture emerges. Table 4 shows that despite differences in the precise nature of the tools referred to in each survey, once we look beyond personal web pages the gap between the major party candidates and their Green counterparts closes considerably. In particular, Green candidates are consistently more likely to have a profile on a social network site, and just as likely to use a video-sharing site such as YouTube or the microblogging service Twitter.

Based on a supply-side analysis of web campaigning in Australia, therefore, the cyclical hypothesis is largely supported. There has been a shift from a situation of normalisation to one more closely approximating equalisation. Despite their much higher level of enthusiasm for web campaigning, minor party candidates were becoming increasingly outnumbered online. The arrival of social media appears to have restored some parity to their online presence and web campaigning efforts. Tools such as social network sites provide new and very popular spaces for parties to build up their support bases, and also to allow 
Table 4: The Use of Web Campaigning, 2007 and 2010 (per cent)

\begin{tabular}{|c|c|c|c|c|}
\hline & Lib-Nat & Labor & Green & \\
\hline \multicolumn{5}{|l|}{2007} \\
\hline \multicolumn{5}{|l|}{ Web 1.0} \\
\hline Email newsletter & 30 & 25 & 36 & $($ Chi-sq $=2.42 p=0.30)$ \\
\hline Advertised email/webpage & 52 & 60 & 61 & (Chi-sq $=1.25 p=0.54)$ \\
\hline \multicolumn{5}{|l|}{ Web 2.0} \\
\hline Pages on social networking site & 35 & 30 & 37 & (Chi-sq $=0.80 p=0.67$ ) \\
\hline Podcasting & 3 & 3 & 4 & (Chi-sq $=0.17 p=0.92$ ) \\
\hline Videodiary/vodcasting & 10 & 10 & 15 & (Chi-sq $=1.88 p=0.39)$ \\
\hline Personal weblog or blog & 13 & 6 & 20 & (Chi-sq $=7.91 p=0.02$ ) \\
\hline Online chats with voters & 0 & 6 & 11 & (Chi-sq $=7.60 p=0.02)$ \\
\hline \multicolumn{5}{|l|}{2010} \\
\hline \multicolumn{5}{|l|}{ Web 1.0} \\
\hline E-news/bulletin & 55 & 44 & 51 & (Chi-sq $=1.34 p=0.51)$ \\
\hline Email & 91 & 90 & 85 & (Chi-sq $=1.35 p=0.50)$ \\
\hline \multicolumn{5}{|l|}{ Web 2.0} \\
\hline Social networking sites & 48 & 49 & 62 & (Chi-sq $=3.36 p=0.19)$ \\
\hline Flickr & 0 & 4 & 3 & $($ Chi-sq $=1.82 p=0.40)$ \\
\hline Video-sharing sites & 28 & 12 & 18 & (Chi-sq $=4.02 p=0.13)$ \\
\hline Campaign blog & 36 & 34 & 19 & (Chi-sq $=6.33 p=0.04)$ \\
\hline Twitter & 25 & 20 & 21 & $($ Chi-sq $=0.61 p=0.74)$ \\
\hline
\end{tabular}

Notes: The questions were: (2007) 'Did you provide any of the following services during the election campaign?' (2010) 'Below is a list of internet-related tools that can be used to communicate with voters during elections. For each one please say how important they were for you in the election campaign'.

Sources: Australian Candidate Studies, 2007 and 2010.

their supporters to organise on their behalf. That said, the increasing tendency among major party candidates to produce personal pages and their growing recognition that web campaigning matters suggests a more subtle pattern of dominance. Personal web pages are increasingly professionalised operations which require the input of trained web designers. Minor parties facing these higher entry costs may well have decided to save their resources by developing profiles on these free platforms. From this perspective, the adoption of social media might in itself be an indication of weakness and underscore the increasing marginality of the smaller parties online.

To evaluate fully the normalisation versus equalisation debate we undertake a final analysis of the impact of these various web campaign tools on one key measure of success - levels of voter support. If it is the case that a purpose-built personalised web presence is more appealing to voters and generates more support than social media sites, then the idea that minor parties are equalising their ability to compete with the major parties is placed into question. Alternatively, if by building their profiles in these popular online social spaces smaller parties are managing to interact with the voters and attract electoral support, then this may signal an increase, if not an equalisation, in their competitive capacity. By 
focusing on vote winning as the measure of success we should stress that we do not exclude the possibility that minor parties are gaining from their efforts in other ways. In particular, through social network sites and tools like Twitter they are likely to be able to raise awareness, recruit new volunteers and also raise funds. On a practical level, however, adding in these aspects of performance is problematic since it becomes more difficult to measure them in a systematic manner at the constituency level. Moreover, one can argue that these 'softer' dimensions of success are ultimately undertaken to help improve the parties' capacity to attract votes. On grounds of overall efficiency and consistency, therefore, we take a more reductionist approach and use vote as the most reliable and accessible means of evaluating the impact of a website.

\section{The Electoral Consequences of Web Campaigning}

The final step in the analysis is to model the impact of the various types of web campaigning on the vote for the three sets of party candidates, Liberal-National, Labor and the Greens. Since it is necessary to analyse the three sets of party candidates separately this significantly reduces the number of cases available. ${ }^{8}$ To address this problem we combine the 2007 and 2010 samples which represent the two elections where we have most complete information about the uptake of various types of web tool. This provides a sample size of 117 for the Liberal-Nationals, 134 for Labor and 197 for the Greens.

Studies of the effect of e-campaigns on voter behaviour are limited but what has been carried out has suggested that web campaigns are linked to electoral success. Early work by Dave D’Alessio (1997) demonstrated a positive and significant effect of having a website on US Congressional candidates' vote. Subsequent analyses of candidates in Irish and Australian elections supported these conclusions with models that used a much wider range of controls (Gibson and McAllister, 2006; Sudulich and Wall, 2010). None of these studies were conceived of in terms of tests of the normalisation or equalisation hypotheses, however, and so could not inform us as to whether party size was linked to the effectiveness of the web campaign in mobilising support.

We build on these models by including a wide range of control variables and adding in a variable to distinguish the type of e-campaign tools used. More specifically we divide the web campaign into three types - having a personal website (coded 1 if they had a website and zero if not), using Web 1.0 tools, and using Web 2.0 tools (both as defined in Table 3 and measured as cumulative scores, then standardised). In order to specify properly the effect of web campaigning on the vote, a range of controls are required. First, the model controls for traditional (non-web) campaigning, measured here by the number of hours per week spent during the campaign on canvassing, direct mailing, telephoning and on radio, television and newspaper interviews. Second, the model controls for the candidates' individual resources (measured by age, gender and education) and, third, for their political resources (incumbency, length of party membership, whether or not they live in the constituency, the number of party workers they could count on during the campaign, and prior preparation for the campaign). ${ }^{9}$ Finally, we include as a control a dummy variable for the year in which the survey was conducted. Our dependent variable is the percentage first preference vote that the candidate received in the election. Full details of all the variables and coding are provided in the Appendix. 
Table 5: Candidates' Web Campaigning and the Vote, 2007 and 2010 (OLS Regression)

\begin{tabular}{|c|c|c|c|c|c|c|}
\hline & \multicolumn{2}{|c|}{ Lib-Nat } & \multicolumn{2}{|c|}{ Labor } & \multicolumn{2}{|c|}{ Green } \\
\hline & $b$ & beta & $b$ & beta & $b$ & beta \\
\hline \multicolumn{7}{|l|}{ Web campaigning } \\
\hline Personal website & 2.54 & 0.10 & $2.36^{*}$ & $0.11^{*}$ & 0.16 & 0.02 \\
\hline Web 1.0 & 0.33 & 0.02 & -0.56 & -0.04 & -0.01 & -0.01 \\
\hline Web 2.0 & $-1.34^{*}$ & $-0.13^{*}$ & -0.39 & -0.04 & $0.38^{* *}$ & $0.14^{* *}$ \\
\hline $\begin{array}{c}\text { Traditional campaigning } \\
\text { (hours per week) }\end{array}$ & 0.03 & 0.04 & 0.03 & 0.07 & 0.01 & 0.02 \\
\hline \multicolumn{7}{|l|}{ Individual resources } \\
\hline Age (years) & -0.12 & -0.10 & $-0.23^{* * *}$ & $-0.19 * * *$ & -0.01 & -0.02 \\
\hline Gender (male) & -0.04 & -0.01 & 0.66 & 0.03 & $-1.14^{* *}$ & $-0.13^{* *}$ \\
\hline Tertiary education & -3.42 & -0.11 & 0.64 & 0.02 & 1.78 & 0.11 \\
\hline \multicolumn{7}{|l|}{ Political resources } \\
\hline Incumbency & $14.48^{* * *}$ & $0.58^{* * *}$ & $12.66^{* * *}$ & $0.53^{* * *}$ & $\mathrm{n} / \mathrm{a}$ & \\
\hline $\begin{array}{l}\text { Length party } \\
\text { membership (years) }\end{array}$ & $0.23^{* * *}$ & $0.22^{* * *}$ & $0.23^{* * *}$ & $0.25^{* * *}$ & $0.12^{* *}$ & $0.13^{* *}$ \\
\hline Live in constituency & $3.67^{*}$ & $0.12^{*}$ & -0.68 & -0.02 & 0.92 & 0.10 \\
\hline Party workers (number) & -0.03 & -0.01 & $0.21^{* *}$ & $0.14^{* *}$ & 0.02 & 0.04 \\
\hline $\begin{array}{l}\text { Length of campaign } \\
\text { preparation (months) }\end{array}$ & 0.08 & 0.03 & 0.10 & 0.03 & $0.16^{*}$ & $0.13^{*}$ \\
\hline Year of survey (2007) & $1.38^{* *}$ & $0.17^{* *}$ & $-2.57^{* * *}$ & $-0.35^{* * *}$ & $1.21^{* * *}$ & $0.43^{* * *}$ \\
\hline Constant & $-2,691.01$ & & $5,199.61$ & & $-2,413.31$ & \\
\hline Adj R-squared & 0.56 & & 0.58 & & 0.19 & \\
\hline $\mathrm{N}$ & 117 & & 134 & & 197 & \\
\hline
\end{tabular}

Notes: Ordinary least squares regression coefficients predicting the percentage first preference vote in the 2007 and 2010 elections. Variables are scored zero or one unless otherwise noted. Web 1.0 and 2.0 are standardised scores based on the number of internet tools used, as defined in Table 3.

*** Statistically significant at $p<0.01 ;{ }^{* *} p<0.05 ;{ }^{*} p<0.10$.

Sources: Australian Candidate Studies, 2007 and 2010.

The results in Table 5 show that web campaigning does indeed have a significant effect on the vote, net of a wide range of other factors. ${ }^{10}$ Maintaining a personal website increases the vote both for Liberal-National and for Labor candidates, although the effect is small (just over 2 per cent of the vote in each case, net of other things) and is statistically significant only for Labor candidates. There is no significant effect for having a personal web page among Green candidates. By contrast, greater use of Web 2.0 tools has no positive impact on support for major party candidates but significantly increases the vote for Green candidates. Indeed, for Green candidates, using Web 2.0 is the most significant factor in the model, after the year of survey. Using Web 1.0 tools has no significant impact on the vote for any of the party candidates, possibly due to their ubiquity in these more recent elections. A final finding is that Liberal-National candidates using Web 2.0 tools see a significant reduction in their vote. This is a rather surprising finding that we return to in our conclusion. 
Among the other variables in the model, the use of traditional forms of campaigning, such as canvassing, has no significant impact on the vote for any of the three parties. This further emphasises the importance of the different forms of web campaigning in winning votes. On a more personal or demographic level the characteristics of candidates appear to be relatively unimportant in determining the vote that they receive. The lack of any impact for higher education is explicable in that this population is a self-selected body of highly motivated and politically interested people. As such we would expect education levels to be less varied and important in determining candidates' election results. Age matters only for Labor, with its younger candidates performing significantly better than older ones. In terms of gender, female Green candidates receive more votes than their male counterparts. In terms of political resources, length of party membership increases the candidate's vote in all three parties, reflecting the importance of party networks and commitment in gaining selection for a winnable seat. Being able to count on party workers increases the vote for Labor candidates, and early campaign preparation significantly benefits Green candidates. ${ }^{11}$

These results are important in that they confirm the findings from earlier studies that engagement in web campaigning appears to be linked to an increase in the level of electoral support that a candidate receives. From the perspective of this study the findings indicate that a more complex situation exists beyond the simple pendulum swing model set out so far. The results support the idea that minor party candidates' use of digital campaign tools is linked to an improved electoral performance and thereby they support the hypothesis that cheaper social media technologies are helping minor parties to become more competitive. However, although the major parties do not make the same gains from their Web 2.0 campaign efforts and in some cases actually suffer, they do appear to reap considerable rewards from having a personal web page. For mainstream left-wing candidates in particular, use of the web in their campaign is strongly linked to an improved electoral position and the vote gain for personal pages is actually greater than for social media. As such, it appears ceteris paribus that the web does offer a greater advantage for certain major party candidates over their minor party rivals.

\section{Conclusion}

The growing use of the web in the political arena has sparked an ongoing debate over the extent to which this will challenge the power of political elites. For political parties, this discussion has centred on the extent to which use of the internet is increasing the ability of smaller parties to compete for voters' attention and has been captured by the contrasting scenarios of normalisation and equalisation. Rather than seeing them as rival hypotheses as much of the literature has done, we have argued that they are better understood as distinct phases that map on to technological developments within the medium itself. An early period of experimentation and equality was displaced by a move to the provision of increasingly resource-hungry personalised sites which led to the dominance of major party candidates online. This latter trend was then challenged by the growing colonisation of alternative Web 2.0 spaces by the minor parties.

The results of our analyses have provided support for this interpretation, although the picture is more complex than the simple pendulum swing model suggests. While we were not able to test the very first stages of adoption, we found that despite smaller party 
candidates consistently placing more value on web campaigning, there has been a growing dominance by the major parties as measured by the adoption of personal websites. This superiority was, however, challenged by the entry of low-cost Web 2.0 tools which have been used primarily by the minor players. While this latter development may hold the potential to boost the profile of non-established candidates, this has occurred alongside an increasing recognition among major party candidates of the value of web campaigning. The adoption of Web 2.0 by the smaller parties might simply reflect their more marginal status, cut off as they are from rolling out the more high-specification websites. To test whether this latter surge by the Greens has indeed served to improve their electoral fortunes vis-à-vis those of the larger parties we tested the impact of web campaigning in its various modes on the electorate.

Our findings showed that at least one of the major parties appears to be seeing a return on its investment. Labor candidates with a personal website typically perform significantly better than those without one. Encouragingly, however, Green candidates who exploit the free tools of Facebook and Twitter also appear to perform better than their counterparts not using these social media technologies. Explaining these findings is clearly something for future research to explore. One argument may be that these new online spaces contain more of those young people identified in the wider citizen politics literature who are seeking more direct forms of political engagement and expression and are eschewing conventional party politics (Dalton, 2008). As such they form a fertile new recruiting ground for parties such as the Greens in a way that is not possible for either Labor or the Liberal-Nationals. In addition, the effects of social media campaigning may be magnified due to their highly networked and viral quality which increases their indirect or 'two-step' effect within the electorate. So rather than it being the blogs or Facebook profiles per se that are generating new voters, they provide activists and opinion leaders with a greater opportunity to extend the parties' reach by facilitating the sharing and discussion of information.

For the major parties, personal web pages may also be a means of directly and indirectly converting supporters. The sites themselves help to recruit some new voters; however, given what was reported earlier about the size of the audience for web-based politics it is more likely that any impact is occurring in a 'two-step' fashion. The sites provide tools and resources for party members and activists to extend their influence and engage in voter mobilisation. For an account of this type of 'two-step' effect see Pippa Norris and John Curtice's (2008) explanation of the effects of internet use on voters during the 2005 UK general election. If this interpretation is correct then these findings would suggest that the Labor Party has been particularly successful in unlocking the secrets of this particular type of two-step online campaigning. However, it may also serve as a proxy or indicator of a wider competence in running a professionally designed and technologically sophisticated campaign. By implication, the negative association between social media campaigns and coalition candidates' support levels might indicate that the latter are more likely to run poor-quality Web 2.0 campaigns and are being punished for it. More realistically, however, this may say something about the particular group of Liberal-National candidates who adopt Web 2.0 - that they are among the least likely to succeed and so use the medium as a last resort. This 'no-hoper' effect is not explicitly tested here but would be something for future research to investigate. 
Overall, the findings from this study are generally supportive of a linear trend toward normalisation rather than a cyclical move from major party dominance to equalisation. The major parties in Australia are clearly investing more in their web campaigns and appear to be enjoying significant electoral rewards as a result. That said, where smaller parties are investing their efforts appears to be the very spaces in which increasing numbers of younger voters are congregating. As a result, their appropriation of the newer digital tools means that their ability to recruit and convert supporters may increase further in future elections. While it remains to be seen how active supporters operating in these new spaces are, if they do attract a more engaged pool of supporters then the effects of such activities will be further magnified.

Of course, once the major parties see the prospect of electoral returns from Web 2.0 then this may lead them to utilise these tools more effectively. Placing these results in a wider geographic context, the recent US presidential election clearly demonstrates that the web has become a key campaign tool, not just for communicating a message but for mobilising support bases on the ground (Gibson, 2013). The prospects for 'real' electoral gains and new reservoirs of campaign volunteers that Obama generated are likely to prove a strong clarion call to Western party elites who are struggling to retain and recruit members. The candidate-centred nature of the American system and its high-frequency electoral cycle, however, arguably offer the ideal laboratory for such innovation compared to the more centralised party systems of Australia and Western Europe (Anstead and Chadwick, 2008). In addition, the tighter levels of discipline and central party control over candidate selection which typically operate in these environments may make the established parties reluctant to promote too heavily these new and more open channels of communication. Twitter in particular provides a new highly public platform for offmessage commentary from naïve or wayward candidates which can then generate unwelcome mainstream media headlines. It remains to be seen, therefore, whether those more 'responsible' parties can move quickly and convincingly enough to crack open the new social media markets.

\section{Appendix}

The Australian Candidate Study (ACS) surveys have been conducted since 1987 in parallel with the Australian Election Study surveys of voters (see http://aes.anu.edu.au/). The ACS is a post-election mail-out, mail-back survey which receives extensive support from all of the political parties in order to achieve an effective response rate, including a personally signed letter from each party's central office encouraging completion of the questionnaire. In 2001 the response rate was 56.8 per cent; in 2004, 53.6 per cent; in 2007 , 49.9 per cent; and in 2010, 45.5 per cent. The 2001, 2004, 2007 and 2010 surveys used here were conducted among House of Representatives and Senate candidates. An anonymised version of the unit record file is publicly available from the Australian Data Archive (http://www.assda.edu.au/).

The analyses presented here are based on candidates who stood for the House of Representatives for the Labor, Liberal, National or Green Parties. In each election, all candidates standing for these parties were surveyed. The survey is therefore cross-sectional, although there is a small panel component in that a small group of incumbent candidates 
who were re-elected at each of the elections will have completed the survey in two or more elections. However, since incumbents are a small minority of the candidates surveyed in each election (never more than one in five), this panel component is negligible.

In Table 5 the variables are defined as follows. The dependent variable is the first preference vote received by each candidate in the lower House of Representatives in either the 2007 or the 2010 election. Personal website is a binary variable and coded 1 if they had a website and zero if not. Web 1.0 and Web 2.0 are based on the questions in Table 3, and are cumulative scores based on the number of web tools the candidate reported using. Since the scales differed between the two surveys, they were standardised to Z scales, with a mean of zero and a standard deviation of one. Traditional campaigning combines the hours per week that each candidate reported spending during the campaign on canvassing, direct mailing, telephoning and on radio, television and newspaper interviews. The question was 'Please indicate below how many hours per week you spent on each of the following activities in your campaign ... doorknocking, canvassing ... organising direct mailing ... speaking on the telephone ... radio and television interviews ... newspaper interviews'. Age is measured in years, and gender, tertiary education and incumbency are measured as dummy variables. Length of party membership is measured in years and is based on the question 'In what year did you join the political party for which you are now a candidate?' Living in the constituency is a dummy variable and is based on the question 'Do you live in the electorate for which you stood as a candidate?' Party workers is the number of workers available during the candidate's campaign and is based on the question 'Approximately how many party workers could you count on to work for your campaign on an average day?' Length of campaign preparation is measured in months and is based on the question 'How long before the election did you begin to organise your campaign?'

\section{(Accepted: 30 May 2013)}

\section{About the Authors}

Rachel K. Gibson is Professor of Political Science at the Institute for Social Change (ISC), University of Manchester. Her research interests are in the areas of political communication and new information and communication technologies. She has published several books and articles on the use of digital media in political communication, particularly by parties, and for election campaigning and participation. Rachel K. Gibson, ISC, University of Manchester, Manchester M13 9PL, UK; email: rachel.gibson@manchester.ac.uk

Ian McAllister is Distinguished Professor of Political Science at the Australian National University. His most recent books are (co-author) Conflict to Peace: Society and Politics in Northern Ireland over Half a Century (Manchester University Press, 2013), The Australian Voter (University of New South Wales Press, 2011) and (co-author) Political Parties and Democratic Linkage (Oxford University Press, 2011). He has been Director of the Australian Election Study since 1987. $\mathrm{He}$ is a Fellow of the Academy of Social Sciences in Australia and a corresponding member of the Royal Society of Edinburgh. His scholarly research covers comparative political behaviour, post-communist politics and Northern Ireland and Australian politics. Ian McAllister, Research School of Social Sciences, Australian National University, Canberra, ACT 0200, Australia; email: ian.mcallister@anu.edu.au

\section{Notes}

1 For example, over half of the almost 12 million Facebook users in Australia are aged between 18 and 34, according to findings from commercial research company SocialBakers. Available from: http://www.socialbakers.com/facebook-statistics/Australia [Accessed 19 November 2012]. 
2 The idea of Web 2.0 has been rejected as meaningless by Berners-Lee, the originator of the web, who argues that the web has always been about user-generated content (Anderson, 2007, p. 5).

3 The Nationals are very much the junior partner in this coalition. In the 2010 election, for example, the Nationals had six candidates elected, compared to 66 candidates who were elected for the Liberals.

4 The Greens have always held a number of seats in the Senate which, because of the different electoral system, has a lower barrier to entry. Two other significant minor parties appear in the 2001-10 surveys. The One Nation Party gained a high profile in the 1998 and 2001 elections, winning 8.4 per cent and 4.3 per cent of the vote, respectively, but by 2004 was in terminal decline. Similarly, the Australian Democrats, formed in 1977, won 5.1 per cent and 5.4 per cent of the vote in the 1998 and 2001 elections, respectively, but by 2004 had been eclipsed by the Greens.

5 There is, however, a proportion of the age-eligible population (19.0 per cent in 2010) who are not enrolled, and this is biased toward younger citizens. See http://www.idea.int/vt/country_view.cfm?CountryCode=AU [Accessed 19 June 2012].

6 For candidates' use of personal web pages we have only one binary measure in 2001 and 2004. For the 2007 and 2010 elections we have a battery of items measuring use of e-campaign tools.

7 One possible explanation for the spike in Green candidates' use of web pages in 2004 may be that the central party elites and/or campaign managers placed a particular premium on the internet which was not repeated in subsequent elections due to personnel changes. Having a digital champion or promoter at the higher levels of campaign management can have a major impact on how seriously the internet is taken. The efforts of Joe Trippi, for example, transformed the campaign and fortunes of US Democrat Howard Dean in 2004

8 An alternative approach, which preserves the sample size, is to analyse the party candidates together and insert dummy variables for party. However, preliminary analyses showed that the range of independent variables interacted differently for the Greens compared to the major party candidates. For that reason it was considered important to combine the 2007 and 2010 surveys in order to have a sufficiently large sample size to calculate separate party equations.

9 It would have been possible to control for many more factors, but the relatively small number of cases placed restrictions on the range that could be included here. The eventual choice of independent variables was driven by the previous findings of key studies by Sudulich and Wall (2010) and Gibson and McAllister (2006).

10 The lower R-squared value for the Greens is largely due to the absence of an incumbency variable in this equation.

11 The 'year of survey' variable is included to control for any other factors from that year's sample of candidates that might have affected the outcome not accounted for by the model. It can be interpreted here as showing that Labor candidates surveyed in 2010 performed better than those responding in 2007 while the reverse is true for Liberal-National and Green respondents in 2010.

\section{References}

Anderson, P. (2007) 'What is Web 2.0? Ideas, Technologies and Implications for Education'. Available from: http:// www.jisc.ac.uk/media/documents/techwatch/tsw0701b.pdf [Accessed 20 June 2012].

Anstead, N. and Chadwick, A. (2008) 'The 2008 Digital Campaign in the United States: The Real Lessons for British Parties', Renewal: A Journal of Labour Politics, 16 (3/4), 86-98.

Bratten, C. (2005) 'Online Zealotry: La France du Peuple Virtuel', New Media and Society, 7 (4), 517-32.

Caiani, M. and Parenti, L. (2009) 'The Dark Side of the Web: Italian Right-Wing Extremist. Groups and the Internet', South European Society and Politics, 14 (3), 273-94.

Carlson, T. and Strandberg, K. (2005) 'The 2004 European Parliament Election on the Web: Finnish Actor Strategies and Voter Responses', Information Polity, 10 (3-4), 189-204.

Carlson, T. and Strandberg, K. (2008) 'Riding the Web 2.0 Wave: Candidates on YouTube in the 2007 Finnish National Elections', Journal of Information and Technology and Politics, 5 (2), 159-74.

Castells, M. (1996) The Rise of the Network Society, The Information Age: Economy, Society and Culture Vol. I. Oxford: Blackwell.

Chadwick, A. (2009) 'Web 2.0: New Challenges for the Study of e-Democracy in an Era of Informational Exuberance', I/S: A Journal of Law and Policy for the Information Society, 5 (1), 9-41.

Conway, M. and Domer, D. (2004) 'An Evaluation of New Zealand Political Party Websites', Information Research: An International Electronic Journal [online]. Available from: http://informationr.net/ir/9-4/paper196.html [Accessed 9 November 2012].

Corrado, A. and Firestone, C. (1996) Elections in Cyberspace: Toward a New Era in American Politics. Washington DC: Aspen Institute.

D'Alessio, D. W. (1997) 'Use of the Web in the 1996 US Election', Electoral Studies, 16 (4), 489-501.

Dahlberg, L. (2001) 'The Internet and Democratic Discourse: Exploring the Prospects of Online Deliberative Forums Extending the Public Sphere', Information, Communication \& Society, 4 (4), 615-33.

Dalton, R. J. (2008) The Good Citizen: How a Younger Generation is Reshaping American Politics. Washington DC: CQ Press.

Erlingsson, G. O. and Persson, M. (2011) 'The Swedish Pirate Party and the 2009 European Parliament Election: Protest or Issue Voting?', Politics, 31 (3), 121-8.

Gibson, R. K. (2013) 'Party Change, Social Media and the Rise of “Citizen-Initiated” Campaigning', Party Politics, Online First. doi:10.1177/1354068812472575.

Gibson, R. K. and McAllister, I. (2006) 'Does Cyber-Campaigning Win Votes? Online Communication in the 2004 Australian Election', Journal of Elections, Public Opinion and Parties, 16 (3), 243-63.

Gibson, R. K. and Ward, S. (1998) 'UK Political Parties and the Internet: "Politics as Usual” in the New Media?', Harvard International Journal of Press/Politics, 3 (3), 14-38. 
Gibson, R. K. and Ward, S. (2003) 'Letting the Daylight In? Australian State Parties and the WWW', in R. K. Gibson, P. Nixon and S. Ward (eds), Political Parties and the Internet: Net Gain. London: Routledge, pp. 139-61.

Gibson, R. K., Margolis, M., Resnick, D. and Ward, S. (2003a) 'Election Campaigning on the WWW in the US and UK: A Comparative Analysis', Party Politics, 9 (1), 47-76.

Gibson, R. K., Römmele, A. and Ward, S. (2003b) 'German Parties and Internet Campaigning in the 2002 Federal Election', German Politics, 12 (1), 79-104.

Gibson, R. K., Cantijoch, M. and Ward, S. (2010) 'Citizen Participation in the Ecampaign', in R. K. Gibson, A. Williamson and S. Ward (eds), The Internet and the 2010 Election: Putting the Small 'p' Back in Politics? London: Hansard Society, pp. 5-18. Available from: http://www.hansardsociety.org.uk/files/folders/2690/download.aspx [Accessed 9 November 2012].

Gueorguieva, V. (2008) 'Voters, MySpace and YouTube: The Impact of Alternative Communication Channels on the 2006 Election Cycle and Beyond', Social Science Computer Review, 26 (3), 288-300.

Harfoush, R. (2009) Yes We Did: An Inside Look at How Social Media Built the Obama Brand. Berkeley CA: New Riders.

Hindman, M. (2009) The Myth of Digital Democracy. Princeton NJ: Princeton University Press.

Jackson, N. (2007) 'Political Parties, the Internet and the 2005 General Election: Third Time Lucky?', Internet Research, 17 (3), 249-71.

Kalnes, O. (2009) 'Norwegian Parties and Web 2.0', Journal of Information Technology and Politics, 6 (3-4), $251-66$.

Koc-Michalska, K. and Vedel, T. (2009) 'The Internet and French Political Communication in the Aftermath of the 2007 Presidential Election'. Paper presented at the 5th European Consortium for Political Research General Conference, Potsdam, Germany.

Lilleker, D. G., Koc-Michalska, K., Schweitzer, E. J., Jacunski, M., Jackson, N. and Vedel, T. (2011) 'Informing, Engaging, Mobilizing or Interacting: Searching for a European Model of Web Campaigning', European Journal of Communication, 26 (3), 195-213.

Margolis, M. and Resnick, D. (2000) Politics as Usual: The Cyberspace 'Revolution'. Thousand Oaks CA: Sage.

Margolis, M., Resnick, D. and Wolfe, J. (1999) 'Party Competition on the Internet in the United States and Britain', Harvard International Journal of Press/Politics, 4 (4), 24-47.

Negroponte, N. (1995) Being Digital. New York: Alfred A. Knopf.

Newell, J. L. (2001) 'Italian Political Parties on the Web', Harvard International Journal of Press Politics, 6 (4), 60-87.

Norris, P. (2001) Digital Divide: Civic Engagement, Information Poverty, and the Internet. Cambridge: Cambridge University Press.

Norris, P. (2003) 'Revolution, What Revolution? The Internet and US Elections, 1992-2000', in E. C. Kamarck and J. S. Nye (eds), Governance.com: Democracy in the Information Age. Washington DC: Brookings Institution, pp. 59-80.

Norris, P. and Curtice, J. (2008) 'Getting the Message Out: A Two-Step Model of the Role of the Internet in Campaign Communication Flows during the 2005 British General Election', Journal of Information Technology and Politics, 4 (4), 3-13.

O'Reilly, T. (2005) 'What is Web 2.0?' Available from: http://oreilly.com/web2/archive/what-is-web-20.html [Accessed 28 June 2012].

Rash, W. (1997) Politics on the Nets: Wiring the Political Process. New York: W. H. Freeman.

Rheingold, H. (1993) The Virtual Community: Homesteading on the Electronic Frontier. Reading MA: Addison-Wesley.

Schweitzer, E. (2005) 'Election Campaigning Online: German Party Websites in the 2002 National Elections', European Journal of Communication, 20 (3), 327-51.

Schweitzer, E. (2008) 'Innovation or Normalization in E-Campaigning? A Longitudinal Content and Structural Analysis of German Party Websites in the 2002 and 2005 National Elections', European Journal of Communication, 23 (4), 449-70.

Schweitzer, E. (2011) 'Normalization 2.0: A Longitudinal Analysis of German Online Campaigns in the National Elections 2002-9', Journal of Computer Mediated Communication, 26 (4), 310-27.

Semetko, H. and Krasnoboka, N. (2003) 'The Political Role of the Internet in Societies in Transition: Russia and Ukraine Compared', Party Politics, 9 (1), 77-104.

Small, T. A. (2008) 'Equal Access, Unequal Success: Major and Minor Canadian Parties on the Net', Party Politics, 14 (1), $51-70$.

Smith, A. and Rainie, L. (2008) 'The Internet and the 2008 Election', Pew Internet and American Life Project. Available from: http://www.pewinternet.org/pdfs/PIP_2008_election.pdf [Accessed 15 June 2012].

Strandberg, K. (2009) 'Online Campaigning: An Opening for the Outsiders? An Analysis of Finnish Parliamentary Candidates' Websites in the 2003 Election Campaign', New Media and Society, 11 (5), 835-54.

Sudulich, M. L. and Wall, M. (2010) 'Every Little Helps: Cyber Campaigning in the 2007 Irish General Election', Journal of Information Technology and Politics, 7 (4), 340-55.

Tkach-Kawasaki, L. (2003) 'Politics@Japan: Party Competition on the Internet in Japan', Party Politics, 9 (1), $105-23$.

Trippi, J. (2004) The Revolution Will Not be Televised: Democracy, the Internet, and the Overthrow of Everything. New York: Regan Books.

Vaccari, C. (2008) 'Surfing to the Élysée: The Internet in the 2007 French Elections', French Politics, 6 (1), 1-22.

Ward, I. (2011) 'Does the Internet Encourage Small Parties? A Case Study of the Minutiae of BC Politics, 1996-2009', Australian Journal of Political Science, 46 (2), 229-42.

Ward, S. and Gibson, R. K. (1999) 'The First Internet Election? UK Political Parties and Campaigning in Cyberspace', in I. Crewe, B. Gosschalk and J. Bartles (eds), Political Communications: The General Election Campaign of 1997. London: Frank Cass, pp. 93-112. 
Ward, S. and Lusoli, W. (2005) 'Logging On or Switching Off? The Public and the Internet at the 2005 General Election', in S. Coleman and S. Ward (eds), Spinning the Web. London: Hansard Society, pp. 13-21. Available from: http:// www.hansardsociety.org.uk/files/folders/68/download.aspx [Accessed 9 November 2012].

Whine, M. (2000) 'Far Right Extremists on the Internet', in T. Douglas and B. D. Loader (eds), Cybercrime: Law Enforcement, Security and Surveillance in the Information Age. New York: Routledge, pp. 234-50.

Williams, C. G. and Gulati, G. (2007) 'Social Networks in Political Campaigns: Facebook and the 2006 Midterm Elections'. Paper presented at the Annual Meeting of the American Political Science Association, Chicago IL, 30 August2 September. 